\title{
UN DIBUJO INÉDITO DE ROGELIO DE EGUSQUIZA, COPIA DEL DIBUJO PREPARATORIO DE LA SIBILA LÍBICA DE MIGUEL ÁNGEL
}

Rogelio de Egusquiza (1845-1915) pintor y grabador, cosmopolita y wagneriano de pro, recogió en su obra tanto las lecciones de los clásicos, como las influencias de los artistas del momento que más admiraba: Messonier, Menzel o Fortuny, de cuyo cenáculo formó parte ${ }^{1}$. Ya muy joven, a los 22 años, manifestó su estimación por los clásicos al pintar un cuadro representando a Miguel Ángel postrándose delante del cadáver de Vittoria Colonna ${ }^{2}$, con el que obtuvo una mención honorífica de segunda clase en la Exposición Nacional de 1867. Una pintura -actualmente en paradero desconocido- citada por Beruete como propiedad de Dña. Consuelo Egusquiza, hermana del pintor $^{3}$ y que, según transcripción de Carretero y Bedia, aparecía en el listado descriptivo de obras propiedad del pintor, realizado por sus descendientes con motivo de la reclamación que éstos hicieron a los distintos centros de recuperación organizados en la posguerra española. Y, si bien el motivo del cuadro evidencia un gran interés por la figura de Miguel Ángel, además, en el mismo listado aparece, como signo inequívoco de veneración hacia el genio renacentista, "una cabeza en bronce tamaño natural, mascarilla de Miguel Ángel", el objeto de culto de los mitómanos novecentistas 4 .

A este tenor es coherente el tema del nuevo dibujo de Egusquiza exhumado hace poco por la galería Artur Ramón de Barcelona (fig. 1). Se trata de una copia del dibujo preparatorio para la Sibila Líbica de Miguel Ángel, que se conserva en el Metropolitan Museum de Nueva York, y es considerado el dibujo de Miguel Ángel más importante de los que actualmente se hallan en Estados Unidos. Pero en este caso, a diferencia del cuadro mencionado, la calidad y la significativa vinculación con el original hacen que el dibujo de Egusquiza vaya más allá de la simple referencia admirativa de manera que, de inmediato, se plantean el cómo, cuando y donde lo realizó.

Egusquiza copió el recto del dibujo a la sanguina dedicado a estudios para la Sibila Líbica -en el verso, hay otros estudios y un pequeño boceto para la figura sentada de la Líbica - catalogado por Tolnay como: Estudio de un joven desnudo para la parte superior del cuerpo de la Líbica, estudio de la mano izquierda de la Sibila, tres estudios del pie izquierdo (fig. 2). No se consideran la cabeza y el apunte del torso que aparecen en la parte central ya que se atribuyen a un discípulo del maestro ${ }^{5}$. En él, Miguel Ángel planteó la sugerente postura de la profetisa Líbica, el giro del torso, caderas y hombros, así como la inteligente resolución del punto de apoyo de la figura, situado en el dedo gordo del pie izquierdo. A la vez es un estudio anatómico masculino para una figura femenina, la de la Sibila que, en el fresco de la bóveda de la Capilla Sixtina, aparece vestida -excepto los hombros, los brazos y el pie izquierdo-, con un bello tocado trenzado, un gran libro abierto en las manos y acompañada de dos Putti, uno con un rollo en la mano. Figura ésta última que, junto con un boceto de la mano derecha de la Sibila, aparece en el dibujo: Estudios para el Putto y para la mano derecha de la Libica y boceto para los esclavos de la Tumba de Julio II ${ }^{6}$ del Ashmolean Museum de Oxford. La Sibila Líbica, calificada ya por Vasari como bellísima, la última de las Videntes que se dirigen hacia el altar, es sorprendida mientras coge o coloca detrás de ella el libro de las profecías ante la llegada del Mesías?.

\footnotetext{
${ }^{1}$ Una puesta al día de su obra se recoge en el catálogo de la última exposición monográfica que se le ha dedicado: Rogelio de Egusquiza 1845-1915. Santander. Museo de Bellas Artes de Santander / Fundación Marcelino Botín, 1995.

2 Ossorio y Bernard, M. Galería biográfica de artistas españoles del siglo XIX. Madrid, 1883-1884, p 192.

3 Beruete y Moret, A. de. En Rogelio de Egusquiza. Pintor y Grabador. Madrid: Blass y Cía, 1918, p 8.

4 CARretero Rebés, Salvador y Bedia CASANUEva, Diego, "Rogelio de Egusquiza (1845-1915): Notas biográficas, bibliográficas y artísticas" en Rogelio de Egusquiza 1845-1915. Santander, 1995, p 59.

5 Tolnay, Charles de. Michelangelo. II The Sistine Ceiling. Princeton: Princeton University Press, 1969, $\mathrm{n}^{\circ} 46$.

6 Íbidem $\mathrm{n}^{\circ} 47$.

7 VASARI (1568, pp 107 f) daba una primera explicación del motivo de las Sibilas: “ La bellísima figura della Libica la quale avenido scritto un gran volume, sta con una attitudine domesca per levarsi in piedi et in un medesimo tempo mostra volare alzarsi e serrare il libro...”. Esta descripción ha sido reconsiderada por autores posteriores que opinan que no guarda el libro sino que lo coge para consultar. Mientras que la situación de la Líbica tan cerca del altar se explicaría por su origen divino (cf. Pausanias Description of Attica, Lib. X, Chap. 12, pp 1 ff, reed. Venecia 1498).
} 

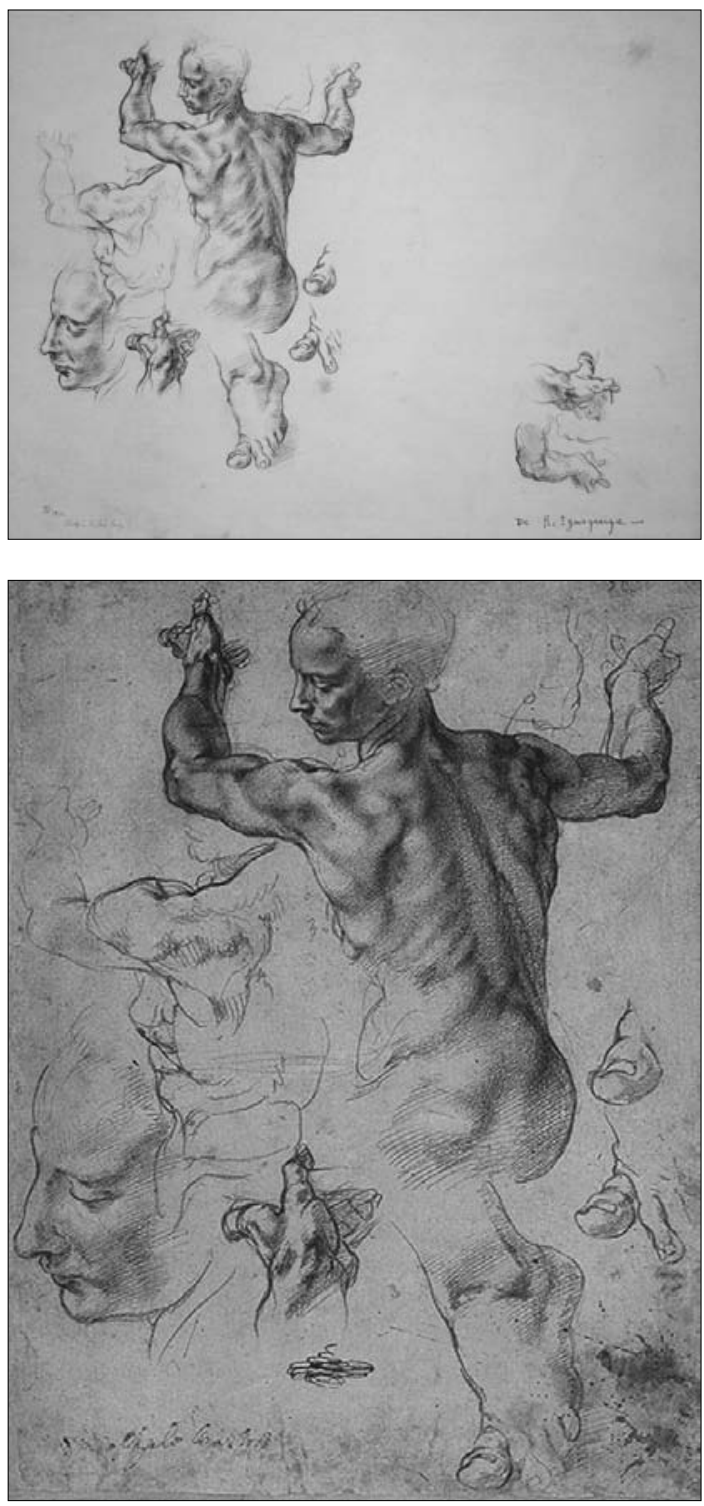

Fig. 1. Rogelio de Egusquiza. D’après Michel Ange. (col. A. Ramón, Barcelona).

Fig. 2. Miguel Ángel. Estudios para la Sibila Líbica

La importancia del dibujo se refleja en una extensa bibliografía y con frecuencia se reproduce como uno de los más destacados en las publicaciones miguelangelescas ${ }^{8}$. Egusquiza lo copió en 1912 tal como se indica en la anotación manuscrita, en francés, con inicial y fecha, en el borde inferior izquierdo del dibujo: “E/1912/D’après Michel Ange”, a la derecha reza: "De R. Egusquiza”. Lo realizó con lápiz negro

${ }^{8}$ La principal bibliografía sobre este dibujo, además del ya citado Tolnay, es: STEINMANN. Michelangelo, Munich, 1905, Band II, p 652, (publicaba una copia de este dibujo que estaba en los Uffizi); FREY, K. Die Handzeichnungen Michelagniolos Buonarroti. Berlin, 1909-1911, 3 vols, $\mathrm{n}^{\circ} 4$; vol I, $\mathrm{n}^{\circ} 4$ y vol II, pp2-4. BRINCKHANN, A. E. Michelangelo-Zeichnungen. Munich, 1925, nº 32; Bryson Burrough. Metropolitan Museum Butlletin, 1925, pp 6ff.; BerEnson, B. The Drawings of the Florentine Painters Chicago, 1938 ( $2^{\mathrm{a}}$ ed.) No $1544 \mathrm{D}$ (recto). 
sobre papel blanco y tiene 25 x 33 cm., unas medidas parecidas al de Miguel Ángel -28,9 x 21,4 cm-, aunque en disposición contraria, ya que aquí la composición es horizontal. Egusquiza copia el dibujo completo y en la parte inferior derecha repite los apuntes de ambas manos de la figura, pero no reproduce la anotación ni la marca, la rúbrica caligráfica, que hay en la parte inferior derecha y central respectivamente del original.

Y si, efectivamente, la cuestión que nos planteamos al principio era donde Egusquiza había visto y copiado el original de Miguel Ángel, la respuesta no ha sido difícil de hallar. El dibujo, inmediatamente después de la muerte de Miguel Ángel, estaba en poder de su familia según recientes investigaciones que demuestran que el " $n^{\circ} 21$ ", anotado en el centro inferior del verso de la hoja, es igual a los que aparecen en otros dibujos que pertenecieron a los Buonarroti. Ingresó, en 1924, en el Metropolitan Museum de Nueva York a través del legado Joseph Pulitzer, procedente, igual que el Retrato de caballero (1590-1600) de El Greco, de la colección española de Aureliano de Beruete. Por consiguiente, entre la ubicación italiana y la norteamericana el dibujo estuvo en España hasta principios del siglo $\mathrm{XX}^{9}$, aspecto que fue estudiado por Manuela Mena y publicado en un revelador artículo ${ }^{10}$ en el que descubre la procedencia y permanencia en nuestro país.

Mena señala que en 1909, Beruete permitió su publicación en el catálogo de Frey ${ }^{11}$ sin aportar datos de su procedencia inmediata ${ }^{12}$, aspecto que la estudiosa desentraña en su estudio demostrando, fehacientemente a nuestro entender, que la marca del dibujo de Miguel Ángel, la rubrica caligráfica hecha con pluma y tinta, es igual a las señales que aparecen en otros dibujos de la colección de la Real Academia de San Fernando de Madrid, procedentes de la colección de Carlo Maratti. Es una marca que no aparece en el Lugt y dista mucho de coincidir con las marcas de la colección de Everhard Jabach, como se sugiere en la actual ficha catalogal del museo neoyorkino ${ }^{13}$.

$\mathrm{Y}$, ciertamente es un dibujo que esta muy reproducido en los libros sobre Miguel Ángel incluso en portadas divulgadoras como la del libro Michelangelo. Life. Drawings 46 works, de la popular editorial Dover.

${ }^{9}$ En la edición de 1973 del El Arte y el Hombre, con el título Estudio muscular y de cabeza para la Sibila Líbica de la Sixtina, todavía se reproducía como de la colección Beruete. Madrid (Barcelona, Planeta, 1973, vol II, p 405), Y en la Gran Enciclopedia Larousse al menos hasta la tirada de 1978, también se cita como de "col. part. Madrid" (Barcelona, Planeta, 1978, vol. 7, p291) .

10 Mena Marqués, Manuela “La procedencia del dibujo de la sibila Líbica de Miguel Ángel en el Metropolitan Museum de Neva York" . Miscelánea de Arte. Madrid: Instituto Diego de Velázquez. Consejo Superior de Investigaciones Científicas. 1982, pp 90-94. Damos las gracias a Dña. Elena Santiago que nos ha proporcionado esta información.

${ }^{11}$ FREY, Karl. Die Handzeichnungen Michelagniolos Buonarotti, Berlin, 1909, vol.I, lám 4, y vol III, pp 2-4.

12 En la monografía laudatoria que Ramón Faraldo dedicó a Beruete se alude a su colección en estos términos casi novelescos: "La pintura, el viaje, el estudio, el cuidado de su colección, que llega a ser una de las más selectas de su tiempo, siguen llenando los años de esta vida. Eran aquellos los tiempos en que todavía, entre un lote de dibujos polvorientos, comprados casi al peso, podía aparecer un Miguel Ángel -como efectivamente apareció una vez, ante la atonía de nuestro pintor, mezclado con otros documentos inanes, en el interior de una vieja carpeta adquirida en un cuchitril-. En las almonedas de las viejas colecciones familiares venidas a menos, los Goya, los Grecos, los Murillos, no eran presas raras. La gestión de Beruete, en esta tarea de descubrimientos, rescate y valoración de especimenes soberbios, que él recupera y cataloga, fue providencial. De unos evita la desaparición; de otros, la destrucción o la confiscación por coleccionistas extranjeros, que por aquel entonces, cuando el exotismo español -con Barrés y con Berrearen y Meunier, a través de la voz apologética de Darío de Regoyos- estaba en auge en Europa, acudían con intención colonizadora, y conquistadora, al reclamo de nuestro arte inexplorado. En ella figuraron: La Purificación, El Cristo de la cruz; el Jesús arrojando los mercaderes del templo y el supuesto autorretrato del Greco; el retrato de María Luisa y alguna otra tela de Goya; el Don Diego de Esquivel de Murillo; Carreño; Lucas, el San Pedro de Velázquez, obras de Constable y de otras primeras figuras inglesas y francesas." FARALDO, Ramón D. Aureliano de Beruete. Pintor. Barcelona, Ediciones Omega, (s.f.), pp 22-23 .

${ }^{13}$ Lugt, Frits. Les marques de collections de dessins\& estampes. Amsterdam, 1921 (ed. Facsímil Alan Wofsy Fine Arts, 1975) nº 29592960 y supl. 2959 a,b,c, ;2979; 2480;2840; supl. 960a; 2122c 2498a, 2991b y supl. 2961-2962. 
Pero volviendo al dibujo de Egusquiza por la fecha -que coincide con el año del fallecimiento de Beruete- no cabe duda que lo realizó después de la publicación del Miguel Ángel en el Frey y antes de su paso a Estados Unidos, mientras estaba todavía en la colección de su amigo, ya que es bien sabida la estrecha relación que mantenían ambos pintores y que compartían aficiones comunes como su amor por Wagner ${ }^{14}$, por Velázquez y por Fortuny y, sin olvidar que fue Beruete quien dedicó a Egusquiza el primer texto sobre su obra ${ }^{15}$.

MARÍA Rosa ViVES Universidad de Barcelona

${ }^{14}$ La relación de Egusquiza con Wagner al que llegó a conocer personalmente esta bien documentada entre otros textos en el catálogo mencionado en la nota 1. Y con respecto a Aureliano de Beruete se decía:-“ No falta ningún año a Bayreuth, con ocasión de las epifanías wagnerianas. Wagner es, acaso, la única debilidad que se permitió al margen de su pintura y de sus pintores. La mascarilla del músico alemán estaba clavada en su casa junto a las obras maestras."-. FARALDO, op. cit., p 24.

15 Es de recordar que Beruete fue autor de notables de textos en francés e inglés sobre Velázquez y Fortuny que propiciaron el conocimiento del arte español en aquellos países: Beruete, A. de. Velázquez. Paris. Henri Laurens, 1898 ( $2^{\mathrm{a}}$ ed. London, Methnen and Co., 1906); A. DE Beruete. "Fortuny" L'Art et les Artistes. Paris, 1912, XVI; Beruete y Moret, A. de "Rogelio de Egusquiza" en Rogelio de Egusquiza: Pintor y Grabador. Madrid: Blass y Cía, 1918, pp 5-30.

AEA, LXXX, 317, ENERO-MARZO 2007, 85-106, ISSN: 0004-0428 